\title{
Keuangan Islam untuk Wong Cilik (Miskin)
}

\author{
Abdul Mughni \\ Peneliti dan Dosen Sekolah Tinggi Ekonomi Islam - Tazkia \\ abdulmughni@tazkia.ac.id
}

\begin{abstract}
Poverty is the wide world problem to the present. Various programs are presented in an effort to reduce and minimize the problem posed. This paper described the approach based on Islamic teachings. It is the combination of the social contract, business and cooperation. It start form social akad, followed by the business and commercial contract, and the last is the risk solving problem. A Comprehensive stage that cannot be directly implemented in stages, and it is good preparation. Meaning the poor in the hadith also indicates the importance of attention of all the parties is not limited to any material deficiencies. Abolishing riba contracts become a compulsory, because the impact of usury posed for the poor. Pairing the word riba in Quran with three words will inspirese the solutions and replacement of such contract.
\end{abstract}

Key words: Islamic Finance, poor society, business contract, Riba

\begin{abstract}
Abstrak
Permasalahan kemiskinan adalah sebuah realitas yang dihadapi dalam dunia, dari sejak dahulu kala hingga saat ini. Berbagai program disajikan dalam upaya untuk mengurangi dan meminimalisir problem yang ditimbulkan. Dalam tulisan ini dipaparkan pendekatan yang bersumberkan dari ajaran Islam. Perpaduan antara akad sosial, bisnis dan kerjasama. Akad sosial menjadi sebuah permulaan, kemudian dilanjutkan dengan akad bisnis dan komersil serta pada tahap akhir diharapkan dapat menghadapi risiko. Sebuah tahapan yang komperhensif yang tidak bisa langsung dilaksanakan melainkan dengan tahapan dan persiapan yang baik. Arti miskin dalam hadis juga mengindikasikan pentingnya perhatian segala pihak tidak hanya terbatas pada kekurangan materi saja. Pengganti dari akad riba adalah sebuah keharusan, karena dampak riba yang ditimbulkan buat sang miskin. Penyandingan kata Riba dalam qur'an dengan tiga kata yang menginspirasi akan solusi dan pengganti dari akad tersebut.
\end{abstract}

Kata kunci: Keuangan Islam, masyarakat kecil, akad bisnis, Riba 


\section{Pendahuluan}

Sudah menjadi sunnatullah bahwa dalam kehidupan dunia ada yang kaya dan miskin. Istilah wong cilik adalah panggilan untuk sekelompok masyarakat yang masih hidup dalam kemiskinan. Dalam hal ini ajaran Islam yang sempurna memiliki ajaran dan program yang dapat digunakan dalam mengharmoniskan hubungan antara sang kaya dan sang miskin. Lahirnya keuangan mikro sebagi upaya dalam menjembatani permasalahan yang ada merupakan bukti lain dari perbedaan penghasilan, dan kemampuan yang memang telah diatur Allah subhanahu wataala, sebagaimana ayat dalam Al Qur'an yang berbunyi:

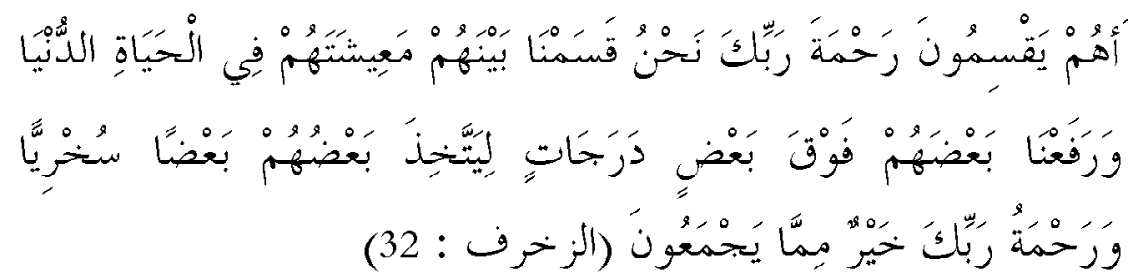

Dengan jelas Allah menyatakan adanya perbedaan penghasilan manusia sehingga kehidupan ini dapat berjalan dan rahmat Allah lebih baik dari harta yang dikumpulkan (tanpa diikuti dengan rasa syukur). Perbedaan yang ada tidak menjadikan manusia yang memiliki untuk menjadi sombong dab takabbur, pada saat yang sama mereka yang kekurangan tidak langsung menjadi orang minder, putus asa dan harapan tetapi melalui keuangan mikro kesenjangan tersebut diharapkan dapat dijembatani dan diperkecil.

Tulisan ini berusaha untuk memaparkan peran yang dimiliki oleh Lembaga Keuangan Mikro Syariah (LKMS) dalam mengentaskan permasalahan sosial secara khusus masalah kemiskinan. Berdasarkan sebuah penelitian yang dilakukan diketahui bahwa perkembangan sektor keuangan mikro mempunyai banyak macam dan modelnya seperti pada tabel di bawah ini 
Tabel 1.

Penelitian atas Lembaga Keuangan Mikro Pedesaan

\begin{tabular}{|c|c|c|c|r|}
\hline Unit resmi & $\begin{array}{c}\text { Setengah } \\
\text { resmi }\end{array}$ & $\begin{array}{c}\text { Jumlah } \\
\text { rekening }\end{array}$ & $\begin{array}{c}\text { Jumlah } \\
\text { peminjam }\end{array}$ & Lain - lain \\
\hline 6.000 unit & 48.000 unit & $\begin{array}{r}45 \text { juta } \\
\text { tabungan }\end{array}$ & $\begin{array}{r}32 \text { juta } \\
\text { peminjam }\end{array}$ & 800.000 kelompok \\
lain
\end{tabular}

Sumber: Bank Pembangunan Asia (Asian Development Bank), 2003

Bercermin dari sejarah, maka sektor keuangan mikro resmi di Indonesia memiliki pondasi di dalam sistem keuangan pedesaan yang umurnya sudah mencapai lebih dari satu abad, yang mencakup berbagai lembaga ditingkat nasional, kabupaten dan desa. Bank pedesaan yang pertama berdiri pada tahun 1895 dan diawal abad ke 20 sudah ada 13.000 lembaga didalam masyarakat, yang secara cepat menggantikan perbankan barter barang (banking in-goods) dengan perbankan uang (banking inmoney). Ini dapat dipandang sebagai faktor yang sangat penting bagi sejumlah besar program dan layanan keuangan mikro dan pedesaan. Kerangka kerja hukum, pengaturan dan pengawasannya lebih bervariasi dibanding hampir setiap negara berkembang yang ada di dunia.

Ada pandangan bahwa kemiskinan akan lebih banyak ditemui di wilayah perkotaan seiring meningkatnya urbanisasi dan krisis ekonomi yang terjadi dalam beberapa tahun terakhir. Padahal sebelumnya kemiskinan diidentikkan dengan fenomena desa atau daerah terpencil yang minus sumber dayanya. Tapi kemiskinan tetap sebagai suatu kondisi sosial yang umumnya invisible dan belum dipahami sepenuhnya oleh para pengambil keputusan, ini pula yang menjadi motif utama pelaksanaan Proyek Penanggulangan Kemiskinan di Perkotaan (P2KP) yang dalam pelaksanaannya menggunakan paradigma dan pemahaman baru.

Pada awalnya kemiskinan selalu dikaitkan dengan faktor ekonomis, yang dinyatakan dalam ukuran tingkat pendapatan (income) atau tingkat konsumsi individu atau komunitas. Lembaga donor internasional seperti Bank Dunia atau Bank Pembangunan Asia (ADB), sebagai contoh, pada periode sebelumnya menggunakan tingkat pendapatan $\$ 1$ per hari sebagai batas proverty line. Sementara di negara-negara berkembang kemiskinan 
diukur dengan tingkat pemenuhan kebutuhan dasar, yang dinyatakan dalam ukuran kebutuhan hidup minimum atau kebutuhan kalori. Pandangan di atas jelas berimplikasi pada pendekatan yang digunakan untuk mengentaskan kemiskinan tersebut. Seperti banyak diterapkan di negara-negara berkembang umumnya upaya pengentasan kemiskinan dilakukan dengan pembangunan yang bertumpu pada pertumbuhan ekonomi. Para pengambil keputusan memandang pertumbuhan output nasional dan regional yang dinyatakan dalam pendapatan perkapita atau GNP dapat mendorong kegiatan ekonomi lainnya (multiplier effect), yang pada gilirannya menciptakan lebih banyak lapangan kerja dan peluang berusaha. Bila skenario ini berjalan sesuai asumsi tersebut, menurut Felix (2008), kemiskinan secara tidak langsung dapat dientaskan.

\section{Perkembangan Keuangan Mikro}

Menurut definisi yang dikeluarkan Micro Credit Summit sebagaimana dikutip Ascarya and Yulizar (2009), keuangan mikro adalah "Program pinjaman uang terhadap keluarga miskin untuk digunakan sebagai usaha yang memberikan hasil dan income dalam memenuhi kebutuhan pribadi dan keluarganya."

Definisi ini jelas menyatakan yang berhak untuk mendapatkan pinjaman tersebut adalah keluarga miskin dengan prinsip pinjaman, tanpa pengecualian apakah si miskin nanti dapat memenuhi dan melunasi hutang atau tidak. Dalam sumber lain yang menjelaskan tentang micro finance disebutkan bahwa

"Keuangan mikro (microfinance) meliputi pinjaman, tabungantabungan, asuransi, layanan transfer, dan berbagai produk keuangan yang ditujukan kepada masyarakat berpenghasilan rendah (lowincome clients)."

Perbedaan terakhir antara micro credit dengan micro finance, dengan penekanan bahwa yang lebih dibutuhkan adalah micro finance karena cakupan bantuan yang lebih luas dalam membantu permasalahan masyarakat miskin tidak terbatas pada aspek pinjaman saja melainkan juga aspek tabungan, asuaransi dan jasa keuangan lain. 
Pada kenyataan di lapangan masih terdapat kerancuan dalam praktek keuangan mikro dalam klasifikasi yang diberikan. Klasifikasinya tersebut ialah kredit limit bagi usaha mikro 0-50 juta. Hal ini terlalu besar, karena pada prakteknya keuangan mikro BMT dan yang lainnya hanya memberikan kredit limit bagi orang miskin yang membutuhkan 0-5 juta rupiah, oleh karena itu perlu definisi ulang tentang klasifikasi kredit limit keuangan mikro seperti yang diusulkan di bawah ini

\section{Tabel 2.}

Usulan kredit limit keuangan Mikro (dalam juta rupiah)

\begin{tabular}{|c|c|c|c|c|c|c|}
\hline CLASS & $\begin{array}{l}\text { CREDIT } \\
\text { LIMIT }^{*}\end{array}$ & ASSET ${ }^{*}$ & $\mathbf{L} \mathbf{A B O R}$ & $\begin{array}{l}\text { BUSINESS } \\
\text { PERMITS }\end{array}$ & COLL'RAL & CLASS \\
\hline $\begin{array}{l}\text { Super } \\
\text { Micro }\end{array}$ & $<5$ & $<10$ & 1 & Not required & NR & Super Micro \\
\hline Micro & $5-50$ & $10-100$ & $1-4$ & Optional & Optional & Micro \\
\hline Small & $50-500$ & $100-1,000$ & $5-19$ & Required & Required & Small \\
\hline Medium & $500-5,000$ & $1,000-5,000$ & $20-99$ & Recpuired & Recuired & Medium \\
\hline
\end{tabular}

Sumber: Ascarya dan Yulizar

Tabel. 3

Kredit Limit, Skema Akad dan Provider Lembaga Berdasarkan Usulan Klasifikasi di Atas

\begin{tabular}{|c|c|c|c|}
\hline CLASS & Credit Limit & Scheme & Provider \\
\hline Charity & $<1$ & Tabarru' & B.Maal T \\
\hline Super Micro & $0 \quad 5$ & Tijarah & B.M.Tamwiel \\
\hline Micro & $5-50$ & Tijarah & BMT / BPRS \\
\hline Small & $50-500$ & Tijarah & BPRS / BUS \\
\hline Medium & $500-5000)$ & Tijarah & BUS \\
\hline
\end{tabular}

Teori di atas adalah konsep keuangan mikro secara konvensional yang perlu di Islamisasi dengan menjadikan syariah dan aturannya sebagai pijakan atau titik tolak, sarana dan tujuan yang ingin dicapai. Keuangan Mikro Islam tidak hanya memperhatikan pada aspek pemberian credit dan finance tetapi lebih dari itu Islam mengajarkan kita untuk memperhatikan 
dan peduli terhadap orang miskin dengan sikap pro aktif tidak menunggu dalam pengertian membantu orang miskin jika diminta, ataupun memberi bantuan bila ditagih saja dst. Dalam hadis Rasulullah menjelaskan tentang definisi miskin yaitu :

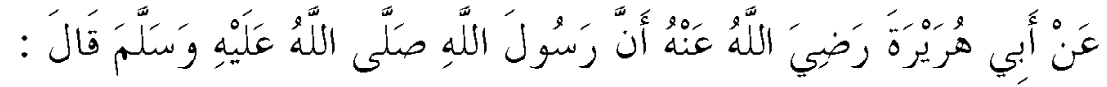

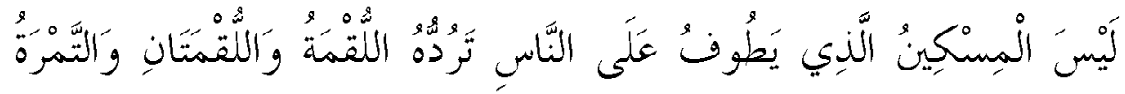

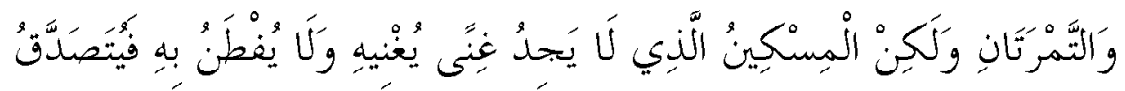

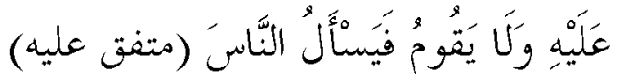

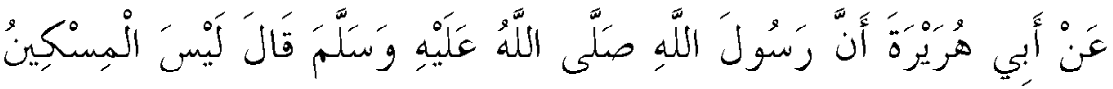

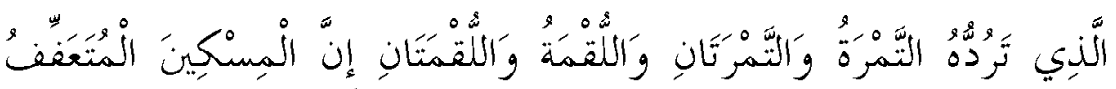

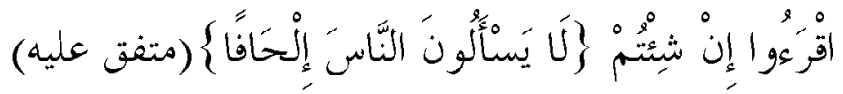

قال الإمام النووي في شرحه على مسلم: الْمِسْكِين الْكَامِل الْمَسْكنَة

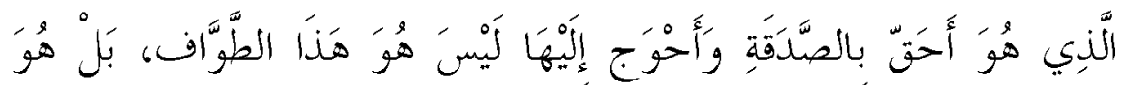

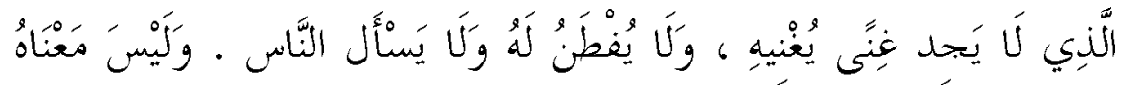

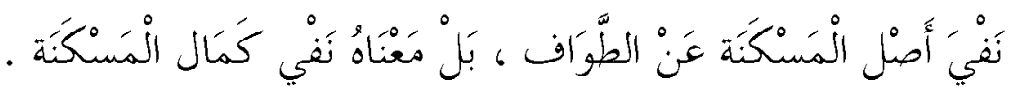

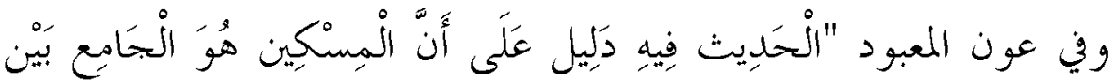

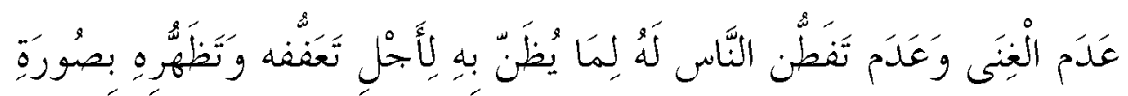

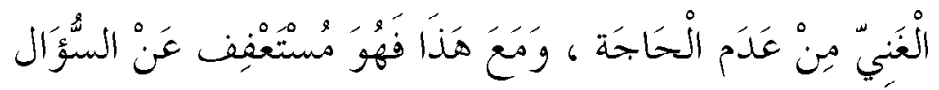


Dua hadis di atas yang diriwayatkan oleh Imam Bukhori dan Muslim memberikan pengertian lain tentang orang miskin, yaitu orang miskin sebenarnya bukanlah orang yang minta-minta tetapi orang yang tidak mendapatkan kepedulian dan perhatian dari orang kaya, tidak pula mendapatkan sedekah untuk memenuhi kebutuhannya. Karena orang miskin sejati mempunyai martabat sehingga ia tidak akan meminta-minta, itulah miskin sesungguhnya yang lebih berhak untuk menerima sedekah, bukan berarti orang yang minta-minta tidak miskin tetapi tidak sempurna kemiskinannya sebagaimana diterangkan oleh Imam Nawawi (1392H), Allah berfirman dalam Q.S. al-Baqarah: 273:

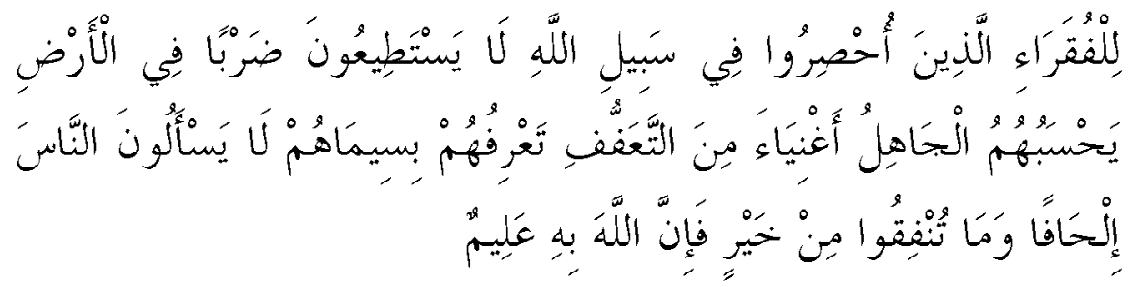

Ayat di atas dengan gamblang menjelaskan bahwa orang miskin tidak akan meminta-minta karena mereka memiliki rasa Iffah atau self-esteem yang membuat mereka tidak akan menghinakan diri dengan menjadi pengemis.

Dari ayat dan hadis di atas kita dapat meyimpulkan tentang teori keuangan mikro dalam Islam mencakup program bantuan charity kepada mereka yang membutuhkan, dengan kata lain keuangan mikro Islam adalah program bantuan sosial kepada orang miskin dilanjutkan dengan memberikan pinjaman modal usaha dan jasa keuangan lainya sesuai dengan prinsip syariah.

Dan menjadi tangung jawab para cendekiawan muslim dalam merumuskan dan merancang bentuk program serta tahapan yang perlu dilakukan dalam upaya mengkombinasikan antara program sosial murni dan dilanjutkan dengan program keuangan yang komersil.

\section{Permasalahan UKM}

Hasil penelitian tim UGM, bekerjasama dengan LPEM-FEUI dan PSPIPB didapatkan beberapa permaslahan yang sering dihadapi oleh UKM. Data 
di bawah ini menjelaskan masalah yang dihadapi dari sisi produksi hingga pemasaran, antara lain:

Dari aspek produksi masalahnya adalah:

1. Kualitas produk rendah

2. Kontinuitas produksi tidak terjamin

3. Inovasi produk rendah

Dari aspek pembiayaan perbankan:

1. Syarat agunan belum mampu dipenuhi

2. Bunga pinjaman terlalu tinggi

3. Pelaku UKM enggan berurusan dengan perbankan, merasa prosedur pengajuan kredit yang rumit.

4. Kurangnya sosialisasi dan informasi mengenai pinjaman lunak yang tersedia untuk mereka.

5. Sistem pembanyaran kembali kredit yang rutin menjadi beban bagi pengusaha yang penjualan produknya berfluktuasi.

Dari aspek Sumber daya manusia masalah yang dihadapi:

1. Rendahnya jiwa wirausaha

2. Skill rendah

3. Tidak mau mengambil tindakan yang dirasa berisiko, sebuah tindakan hanya akan diambil jika mersa yakin bahwa tindakan tersebut pasti aman dan tidak memerlukan pemikiran yang rumit.

4. Puas dengan yang dijalani dan dicapai.

Dari sisi Pemasaran/Promosi

1. Di daerah luar Jawa tidak ada sentra industri kecil, di Jawa terdapat banyak industri kecil yang belum dikelola secara optimal

2. Di luar Jawa tidak memiliki pelanggan tetap.

3. Jaringan pemasaran belum luas

4. Kurangnya event promosi

5. Tidak semua UKM mempunyai kesempatan untuk mengikuti pameran maupun promosi yang diadakan. 
6. Di Jawa pemasaran sangat tergantung kepada pedagang perantara, baik took maupun perusahaan pengepakan dan pedagang besar, sebab produk masuk ke pasar menggunakan merek pedagang perantara

7. Pemasaran menggunakan merek terkenal tanpa lisensi.

Dari sisi Kemitraan masalah yang dihadapi:

1. Kemitraan lebih banyak dalam bentuk pemberian modal lunak

2. Kemitraan dalam bentuk penciptaan jaringan pemasaran banyak ditemukan di DIY, tetapi tidak banyak untuk daerah lain.

3. Koordinasi antara pemberi pinjaman dan Pemerintah Daerah belum optimal/tidak ada

4. Sosialisasi program kemitraan sangat kurang sehingga yang mengetahui program ini hanyalah UKM yang secara langsung memiliki hubungan dengan perusahaan Bapak Angkat.

Dari sisi Manjamen usaha

1. Mengelolaan usaha kurang professional

2. Manjemen usaha bersifat tradisional dam kekeluaragaan

3. Manajemen keuangan: tidak ada pemisahan antara keuangan keluarga dengan perusahaan

4. Manajemen bahan baku kurang diperhatikan

5. Tida ada perencanaan menyeluruh atas proses produksi dan pemasaran

Begitu banyak permasalahan yang dihadapi UKM, karenanya membutuhkan sebuah program terpadu, berjenjang dan bertahap dalam upaya mengatasi permasalahan yang ada. Islam dengan kekayaan intelektual dalam akad-akad fiqh yang telah disusun oleh ulama, memberikan alternatif solusi yang dapat implementasikan untuk menyelesaikan permasalahan tersebut.

\section{Program Keuangan Islam buat Wong Cilik}

Dari teori di atas, Lembaga Keuangan Mikro Syariah menurut Ihsan Arkam (2008) mempunyai lima tahapan dalam menjalankan aktifitasnya sesuai dengan kaidah syariah, secara terinci program tersebut ialah: 
1. Charity Program, program bantuan langsung kepada fakir miskin yang membutuhkan tanpa pamrih dan murni sebagai program sosial, karena mereka sangat membutuhkannya. Dengan menggunakan akad sedekah dan hibah yang diatur dalam fiqh, para pelaku LKMS dapat menghimpun dana zakat, sedekah dan infaq yang dapat langsung disalurkan kepada mereka. Sebagai aksi kongkrit kepekaan dan kepedulian sosial, dilandaskan dari hadis yang menjelaskan tentang kewajiban orang mampu untuk peduli terhadap orang yang membutuhkan selaras dengan sabda nabi Muhammad:

$$
\text { ليس بالمؤمن الذي عنشة رضي الله عنها ، أن رسول الله صلى الله عليه وسلم قال : شبعانا وجاره جائع إلى جنبه (رواه الماكم) }
$$

"Bukan seorang mu'min jika ia tidur dengan perut kenyang sedangkan tetangganya kelaparan.”

2. Program pinjaman, program ini menggunakan akad qardh yaitu pemberian pinjaman tanpa ada tambahan apalagi jaminan dan memberikan keluasaan kepada orang miskin untuk menggunakan dana tersebut sesuai dengan kebutuhanya. Dalam sebuah hadis Nabi bersabda

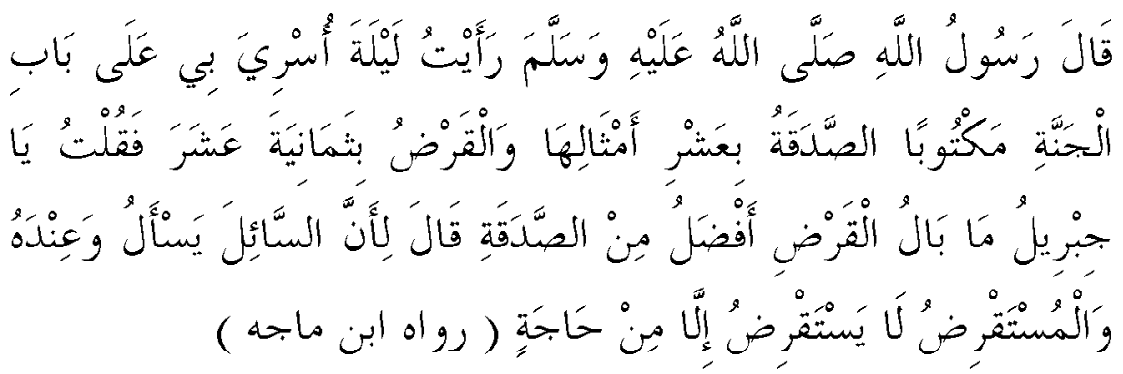

"Pada malam Isra dan Mi'raj aku lihat di pintu surga tertulis "sedekah bernilai pahala 10 kali lipat sedangkan qardh bernilai 18 kali lipat." Aku bertanya kepada Jibril, "kenapa qardh lebih tinggi dari sedekah?" Jawab Jibril, "Orang yang minta sedekah boleh jadi dia adalah orang yang punya, sedangkan qardh pasti karena dia membutuhkan” (Ibnu Majah, 1983).

Melalui akad ini LKMS dapat dengan langsung membantu kaum miskin dengan memudahkan proses pencairan dana pinjaman tersebut. 
Dan diyakini bahwa orang miskin tidak akan mengajukan peminjaman kecuali kepada pihak yang telah mereka kenal dan mereka merasa nyaman, karena sebelumnya LKMS telah memberikan bantuan langsung kepada mereka. Setelah hubungan ini berlangsung dengan baik maka LKMS meningkatkan hubungan melalui program berikutnya yaitu

3. Program financing atau pembiayaan, program ini adalah tahapan lanjutan setelah memberikan bantuna tunai dan pinjaman Qardh, LKMS dalam upaya membantu proses pelunasan pinjaman tersebut, program ini mendidik kaum miskin untuk berusaha hidup mandiri dengan melakukan kegiatan dan usaha yang dapat menghasiulkan income dengan memanfaatkann pembiayaan yang diberikan LKMS. Akad muamalah yang dapat digunakan seperti mudharabah, musyarakah. Diharapkan dengan program tersbut kaum miskin meningkat taraf kehidupannya dan mendapatkan penghasilan tambahan dan dapat melunasi hutang sekaligus memiliki dan mempunyai dana lebih yang dapat ditabung. Dalam banyak ayat Allah menyuruh hambanya untuk berusaha dan bekerja demi terciptanya kemakmuran dibumi, antara lain firman Allah dalam Q.S. Al-Mulk: 15:

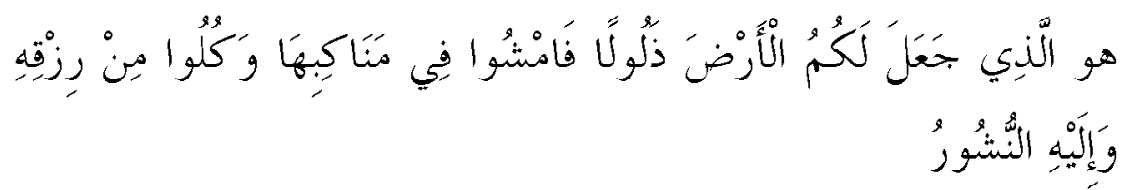

Setelah program ini berjalan baik, LKMS bergerak kepada program berikutnya yaitu

4. Program Saving dan investment, pada program ini LKMS memberikan edukasi kepada kaum miskin agar tidak boros dan konsumtif ketika mendapatkan dana lebih, hasil dari jerih upaya yang telah dihasilkan akan tetapi bersifat ekonomis sebagaimana yang telah dijelaskan dalam Q.S. al-Isra: 30-29:

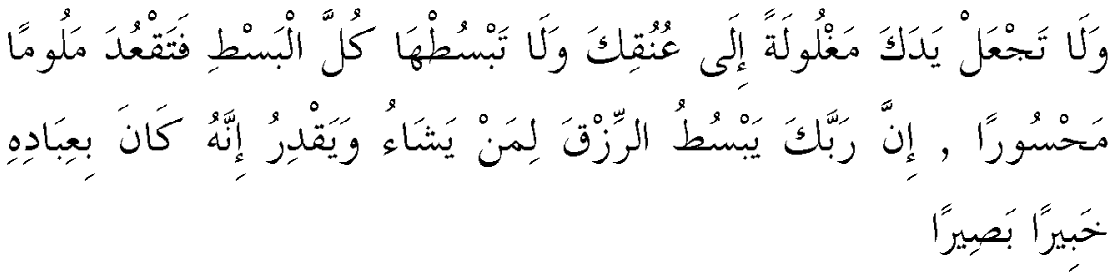


Pada saat yang sama mereka dikenalkan dengan jasa keuangan lainya seperti wadiah dan tabungan mudharabah agar tumbuh budaya menabung walupun sedikit. Karena sanagt penting bagi para pengusaha kecil tabungan, dan mereka mampu untuk itu. Setelah program ini berjalan dengan baik, maka LKMS naik kepada program yang terakhir yaitu:

5. Micro Insurance, program yang bertujuan untuk menumbuhkan semangat saling menanggung (risk sharing), sebagai wujud dan bentuk lain dari kepedulian kepada orang miskin lain. Pada program ini LKMS bisa menjadi penampung dana mikro asuransi dan mengelolanya serta memudahkan proses tanggungan tanpa administrsi yang berbelit-belit dalam memberikan manfaat atau tanggungan bagi anggota yang tertimpa musibah. Dengan demikian terwujudlah perasaan saling berbagi dalam suka dan duka, diantara kaum miskin dan dhuafa .

Bila salah satu dari lima program pokok dan utama penggerak LKMS itu terabaikan, dikhawatirkan LKMS tidak bisa berjalan sesuai dengan misi dan visinya. Jika LKMS hanya terfokus pada program financing dan saving saja, maka tidak ada bedanya dengan micro Banking yang banyak di lakukan lembaga keuangan konvensional. Saat ini jika kita ingin berpartisipasi pada program pengentasan kemiskinan LKMS wajib menjalankan lima agenda pokok di atas.

Kelima program tersebut merupkan pengejawantahan Islamic Micro Finance sebagai solusi dan pengganti sistem ribawi yang dibenci Allah dan rasulnya, hal ini dapat kita fahami tatkala Allah mengharamkan Riba pasti dilanjutkan dengan solusi, tidak berhenti pada aspek pengharamannya saja. Beberapa ayat terkait dengan hal di atas, Q.S. Al Rum: 39; al-Baqarah: 275 dan 276:

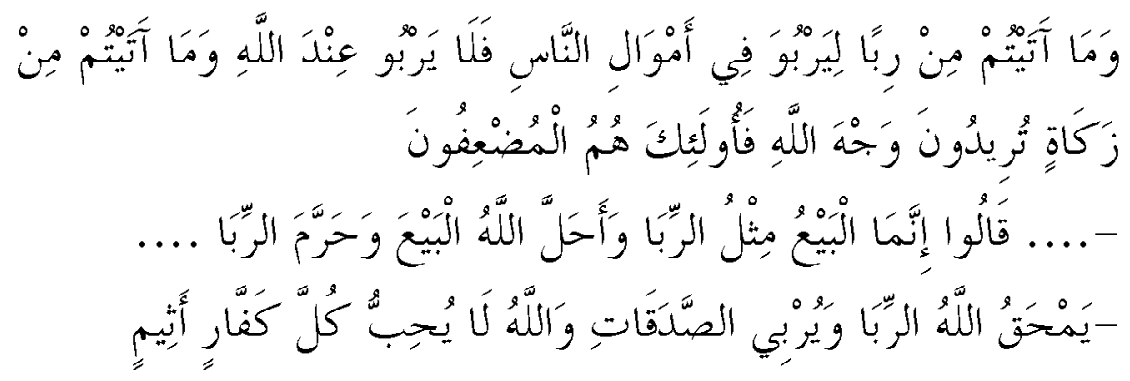


Tiga ayat di atas dengan tegas menjelaskan solusi Islam atas sistem Ribawi, ayat yang pertama Riba disandingkan dengan Zakat, ayat kedua Riba disandingkan dengan Jual Beli, dan pada ayat yang ketiga Riba disandingkan dengan sedekah. Apa artinya? Ketika Allah mengharamkan riba atau menutup satu pintu yaitu riba, pada saat yang sama Allah membuka 3 pintu yaitu zakat, sedekah dan jual beli, sehingga pintu-pintu yang halal tersebut dapat dimanfaatkn manusia dalam memenuhi kebutuhan ekonominya. Maha benar Allah dengan segala firmanya.

Di bawah ini gambar tentang solusi atas riba dan bunga :

\section{Skema 4 \\ Solusi atas Riba dan Bunga}

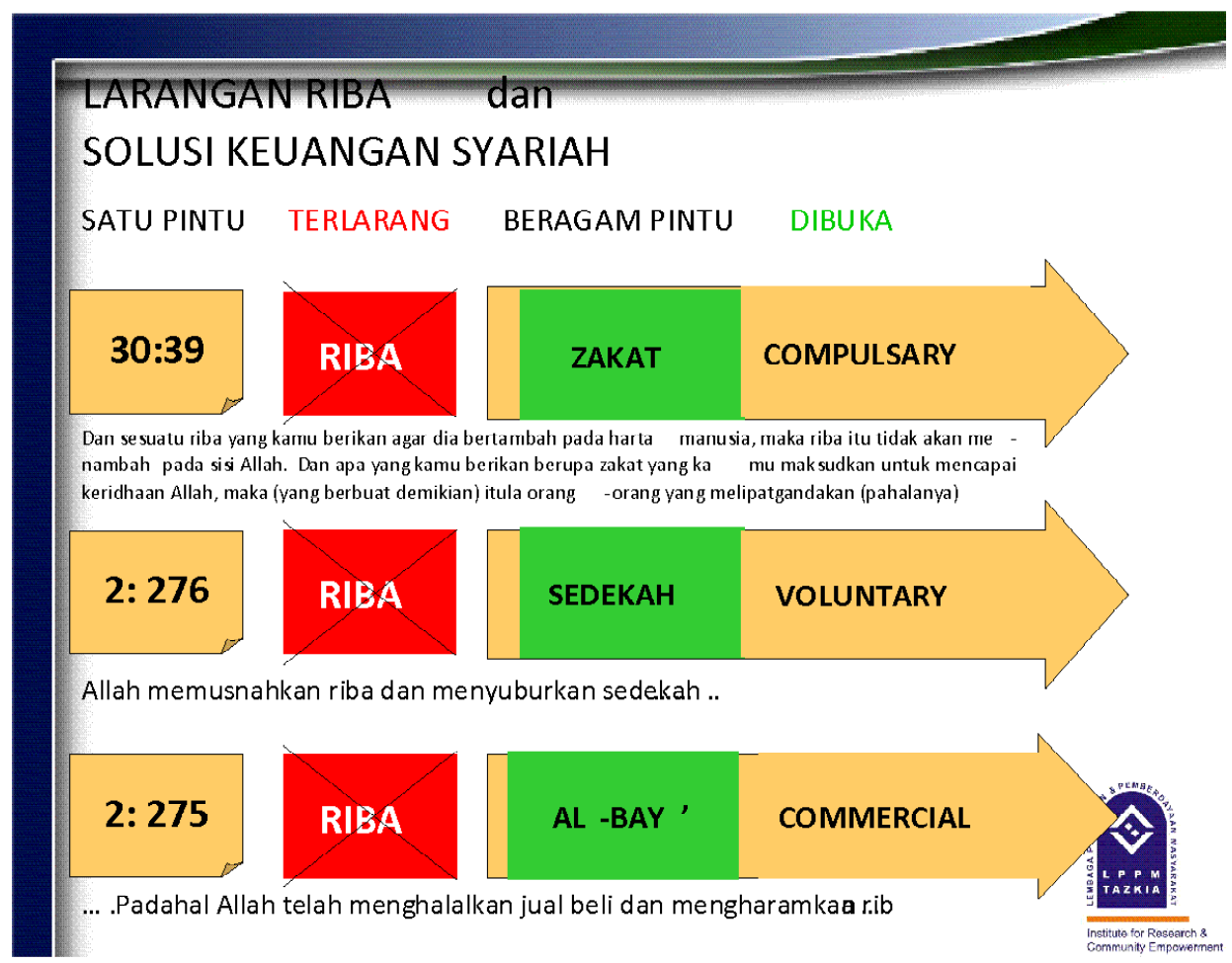

Sumber : Modul Pelatihan Keuangan Mikro LPPM Tazkia, 2008 


\section{Penutup}

Dari tulisan singkat di atas, kita menyadari masih banyak pekerjaan rumah (tugas) yang harus dilaksanakan. LKMS tidak akan bisa dengan sendirinya untuk mengatasi masalah kemiskinan yang begitu kompleks dan pelik, akan tetapi kita tidak boleh bersikap skeptis terhadap peranan dan fungsi LKMS, meskipun masih banyak kekurangan dan permasalahan yang ditimbulkan, fenomena LKMS adalah sebuah kebangkitan baru dan kesadaran yang harus diupayakan untuk selalu tumbuh dan berkembang. Mengingat program keuangan Mikro ini adalah sebuah aksi nyata dalam upaya mengurangi bahkan mengentaskan problem sosial kemiskian yang dapat menjerumuskan umat kepada kekufuran. Oleh karena itu segala kegiatan yang bersifat mendukung dan menunjang program LKMS merupakan bagian integral yang tidak terpisahkan dari Tauhid dan Iman kepada Allah yang telah menganugerahkan manusia segala apa yang ada di muka bumi. Semoga Allah selalu membimbing kita kepada jalan kebenaran amin.

\section{Daftar Pustaka}

Ascarya dan Yulizar D. Sanrego Redefine Micro, Smalll and Medium Enterprises Clasiffication, 2009.

Muhammad Ridwan, Sisdur Pendirian BMT, Citra Media Yogyakarta, 2006.

Chiarra Segrado, Islamic Microfinance and Socially Responsible Investments, paper dari University of Torino dan Dahlia A El Hawary, Islamic Financial Services and microfinance, paper Juni 2005.

Hajjah Salam, MME in Brunei an Islamic Approach, paper for Islamic Conference on Inclusive Islamic Financial Sector Development, Brunei 2007.

Sandra Isnaji, "A case study in Islamic MME Finance: Islamic Financial Services for Poverty Alleviation in the Autonomous Region in Muslim Mindanano", paper Islamic conference on Inclusive Islamic Financial Sector Development, Brunei 2007.

Setyo Budiantoro, "RUU LKM: Jangan Jauhkan Lembaga Keuangan dari Masyarakat" Makalah tidak diterbitkan, 2003. 
Andi Ihsan Arkam, "Lembaga Keuangan Mikro Syariah" makalah dalam Training AISMIF Aceh, 2008.

Adam Felix, Pengentasan Kemiskinan Melalui Pemberdayaan Masyarakat, 2008.

Ibn Majah, Sunan Ibnu Majjah. Riyadh: Syirkah al-Thiba'ah al-“Arabiyah, 1983.

Al-Nawawiy, Abu Zakaria Yahya bin Syaraf bin Mari, Al-Minhaj, Beirut: Dâr Ikhya al-Turats al-Arabiy, $1392 \mathrm{H}$. 